\section{Clause boundaries and recognition latencies for words in sentences}

\author{
DAVID CAPLAN \\ Department of Linguistics \\ Massachusetts Institute of Technology, Cambridge, Massachusets 02139
}

Ss listened to sentences which consisted of two clauses. After the entire sentence was presented, the $S$ either heard (intramodal test) or saw (crossmodal test) a word from the sentence (the probe word). In both the intramodal and crossmodal tests, probe words which were taken from within the final clause of a complex sentence provoked shorter recognition latencies than probe words taken from the first clause. In a second set of controlled experiments, the effect was shown to be independent of intonation contours, serial position, and lexical material. The results argue for a clause-by-clause model of sentence decoding.

Some of the most compelling evidence currently available about sentence perception relates to the initial segmentation of complex and compound sentences. Studies on the subjective localization of extraneous noises ("clicks") occurring during sentences suggest that the segmentation of incoming sentences occurs primarily at the clause (and word) level. Clicks tend to be located at clause boundaries, even in sentences which control for lexical and intonational contours (Garrett, 1965, 1966). On the other hand, it appears that on initial presentation of a stimulus sentence, only clause boundaries "attract clicks"; that is, boundaries between constituents other than clauses do not serve as loci for the subjective localization of clicks.

It has been shown that "probe tasks" are sensitive to syntactic structure. Ss presented with tape-recorded sentences can identify pairs of words from a sentence faster when grammatical relations (e.g., subject of) hold between the words than when this is not so (Walker, 1969a, b, 1970; Walker et al, 1968). If a prime unit of sentence segmentation is the clause, one might expect there to be a systematic difference in reaction latencies for probes in the initial and final clauses of a complex sentence. To test this hypothesis, several experiments were run.

\section{EXPERIMENT 1}

Materials

Six sets of eight sentences were constructed (Appendix A). All sentences were of the form: subordinate clause/main clause and were 12 syllables in length. The clause boundary fell five, four, or three syllables from the end of the sentence. One set of sentences in each of the three groups contained words to be probed which were within the final clause, immediately after the clause boundary, and one set contained words to be probed which were before the final clause, just prior to the boundary. Twenty-four filler sentences were also presented, for which the probe word did not come from the sentence. The probe word was recorded after the sentence, and a high frequency tone recorded on a second tape channel, inaudible to the $S$, activated a millisecond timer at the onset of the probe word. The sentence order was scrambled on the experimental tape.

\section{Subjects}

Eleven M.I.T. paid undergraduate volunteers participated. All were male native English speakers without any history of hearing difficulties.

\section{Procedure}

The Ss were told that they were participating in an experiment in auditory perception. They were to listen to the sentences presented to them and to indicate whether they thought the word coming immediately after each sentence had been in the preceding sentence. If they thought the probe had been in the sentence, they were to press a lever to the position marked IN, if not, they were to press the lever to the OUT position. Ss were instructed to make their responses as quickly as possible and to be as accurate as they could. They were permitted to correct any errors they thought they had made before the presentation of the subsequent sentence. Reaction times and errors were recorded by the $E$.

\section{Results}

The experiment was treated as a 3 by 2 within-groups design (distance of clause boundary from end of sentence by position of probe word vis- $\grave{a}$-vis clause boundary), with lexical material effects confounded with other variables. Analysis of variance was performed on mean reaction times taken across sentences of a given type for each $\mathrm{S}$.

Mean reaction times for the six types of sentences are presented in Table 1. The main effect for position of the clause boundary did not approach significance. The main effect for position of the probe (within vs before the final clause) was highly significant: mean reaction time for the probes in the final clause was $422 \mathrm{msec}$ and for probes before the final clause, $451 \mathrm{msec}(\mathrm{F}=34.222$, df $=1 / 10, \mathrm{p}<.001$ ). The 3 by 2 interaction (Position of Clause Boundary by Position of Probe) was not significant.

\section{EXPERIMENT 2}

The stimuli used in Experiment 1 were reused, except that the probe was presented visually instead of auditorially. A high-frequency noise burst on a second tape channel, inaudible to the $S$, started the tachistoscopic presentation of the probe and the millisecond timer simultaneously. The S's response (made as before) stopped both the timer and the tachistoscopic presentation of the probe. Seven paid volunteers, all M.I.T. male undergraduate native English speakers without history of hearing difficulties, took part. With the appropriate changes indicating that the probe word would be presented visually, the instructions and procedure were the same as in Experiment 1.
Table 1

Mean RT (Milliseconds) for Position of Probe Vis-a-V is Clause Boundary and Position of Boundary Visa-V is End of Sentence: Experiment 1

\begin{tabular}{llccc} 
& & \multicolumn{3}{c}{$\begin{array}{c}\text { Position of Clause Boundary } \\
\text { (Syllables from End of Sentence) }\end{array}$} \\
\cline { 2 - 4 } & In Final Clause & 5 & 4 & 3 \\
\hline Position & Before Final Clause & 452 & 423 & 434 \\
of Probe & Befor & 454 & 448 \\
\hline
\end{tabular}

Table 2

Median RT (Milliseconds) for Potition of Probe Vis-a-V is Clause Boundary and Position of Boundary $V$ ie-a-Vis End of Sentence: Experiment 2

\begin{tabular}{llccc}
\hline & & \multicolumn{3}{c}{$\begin{array}{c}\text { Position of Clause Boundary } \\
\text { (Syllables from End of S gntence) }\end{array}$} \\
\cline { 3 - 5 } & & 5 & 4 & 3 \\
\hline Position & In Final Clause & 875 & 870 & 866 \\
of Probe & Before Final Clause & 984 & 916 & 898 \\
\hline
\end{tabular}


Table 3

Mean RT (Milliseconds) for Position of Probe Vis-a-Vis Clause Boundary by $S$ Groups: Experiment 3

\begin{tabular}{cccc}
\hline & \multicolumn{2}{c}{ Position of Probe Vis-a-Vis Clause Boundary } \\
\cline { 2 - 4 } Groups & $\begin{array}{c}\text { In Final } \\
\text { Clause }\end{array}$ & $\begin{array}{c}\text { Before } \\
\text { Final Clause }\end{array}$ & Total \\
\hline I & 685 & 785 & 735 \\
II & 678 & 817 & 747 \\
Total & 681 & 801 & \\
\hline
\end{tabular}

Table 4

Mean RT (Milliseconds) for Position of Probe $V$ is-a-Vis Clause Boundary by $S$ Groups: Experiment 4

\begin{tabular}{cccc} 
& \multicolumn{2}{c}{ Position of Probe Vis-a-Vis Clause Boundary } \\
\cline { 2 - 4 } & $\begin{array}{c}\text { In Final } \\
\text { Clause }\end{array}$ & $\begin{array}{c}\text { Before } \\
\text { Final Clause }\end{array}$ & Total \\
\hline I & 1093 & 1107 & 1100 \\
II & 915 & 1016 & 965 \\
Total & 1004 & 1061 & \\
\hline
\end{tabular}

\section{Results}

The experimental design was treated as previously. Median reaction times for the six categories of sentences are presented in Table 2. (Median times, rather than means, were used because of the small number of Ss.) Neither the main effect for position of clause boundary nor the interaction of clause boundary with probe position approached significance. The main effect for position of probe with respect to the clause boundary was again highly significant: median reaction time for probes in the final clause was 870 msec; for probes before the final clause, it was $933 \mathrm{msec}$ ( $\mathrm{F}=$ 24.981, $\mathrm{df}=1 / 6, \mathrm{p}<.01$ ).

\section{DISCUSSION OF}

\section{EXPERIMENTS 1 AND 2}

The results of Experiments 1 and 2 indicate that recognition of probes is facilitated when they occur in the final clause of a complex sentence rather than when they occur before the final clause. It must be noted, however, that the experimental materials were not controlled for the varying effects of lexical materials, for intonational clues to the segmentation of the sentence (that is, Ss may have segmented sentences into clauses on the basis of intonation rather than lexical clues), or for the difference in serial position between probes inside the final clause and those before the final clause. To provide a better control for these variables, Experiments 3 and 4 were designed and executed.

\section{MAIN EXPERIMENTS} Experiment 3

Materials. Sixteen pairs of sentences were constructed in which both members of each pair had the same words in the last few positions. The general form of the sentences was: subordinate clause/main clause. The syntactic analysis of the shared words differed, depending upon the initial context: In one member of each pair, the sequence of words in question was segmented so that at least one word fell before the clause boundary, and in the other member, the segmentation was such that this word was within the final clause. For example, consider (1) and (2):
(1) a. Now that artists are working in oil, prints are rare.

b. Now that artists are working fewer hours, oil prints are rare.

(2) a. Whenever one telephones at night, rates are lower.

b. Make your calls after six, because night rates are lower.

A complete list of stimulus sentences appears in Appendix B. Sixteen filler sentences for which the probes did not appear in the sentence were also presented to each $\mathbf{S}$.

The sentences were recorded in a sound-deadened chamber on a master tape. The words from the $b$ versions of the sentences (e.g., oil prints are rare) were spliced onto the initial fragments of the a version (e.g., Now that artists are working in) in such a way that identical copies of the words were present in both the $a$ and $b$ versions. Both naive and alerted judges agreed that all the stimulus sentences sounded natural in the two versions and that they could not tell the sentences had been spliced. The splicing was done in one direction only because splicing in the opposite direction did not produce acoustically acceptable sentences.

After each sentence, a $500-\mathrm{Hz}$ 50-msec low-intensity tone was spliced on to the tape to indicate to the $S$ that the sentence was over. After the tone, $100 \mathrm{msec}$ of leader tape was added, followed by the probe word. A high-frequency noise burst located on a second tape channel, inaudible to the $S$, activated a millisecond timer at the onset of the probe word. The timer was stopped when the $S$ made his response.

Each $\mathbf{S}$ heard Version a on half of the sentence pairs and Version $b$ on the other half. The $S$ s were divided randomly into two groups with respect to whether they heard Version a or Version $b$ of a particular stimulus sentence pair.

Subjects. Sixteen Ss, all M.I.T. undergraduate native English speakers with no history of hearing deficit, volunteered to participate and were paid for their time.
Procedure. As previously, Ss were told to listen to the sentence and to indicate by pushing a lever to one of two positions whether they thought the word following the sentence had been in the sentence or not. Ss were instructed to aim for accuracy and speed in their responses. They were permitted to correct perceived errors verbally.

Results. An analysis of variance was performed on the mean reaction times taken across sentences of a given type. The experiment was treated as a 2 by 2 mixed factorial (2 groups by position of the probed word, within or before the final clause). The differences between the two groups were not significant. The difference between words coming from the final clause and words coming from the initial clause was significant: mean reaction time for probes occurring within the final clause was 681 msec; that for probes before the final clause was $801 \mathrm{msec}(F=11.817, \mathrm{df}=1 / 14$, $\mathbf{p}<.01)$.

\section{Experiment 4}

The same stimulus materials were used, but the probe words were presented visually rather than auditorially. A high-frequency noise burst located on the second tape channel, inaudible to the $S$, started the millisecond timer and the tachistoscopic presentation of the probe at the end of the sentence. The S's response stopped the timer and the presentation of the probe. Ss were instructed, as before, to aim for accuracy and speed in their responses and to correct perceived errors verbally. Sixteen M.I.T. undergraduates participated and were paid for their time.

Results. Experiment 4 has the same experimental design as Experiment 3, and was analyzed in the same way. The difference between groups of Ss was not significant. The difference for words coming from the final clause and words coming from the initial clause was significant: the mean reaction time for probes occurring within the final clause was $1,004 \mathrm{msec}$ and for probes before the final clause, $1,061 \mathrm{msec}(\mathrm{F}=5.524$, df $=1 / 14$, $\mathbf{p}<.05$ ). 


\section{GENERAL DISCUSSION}

Experiments 3 and 4 control for serial position and intonation effects by presenting exactly the same acoustic string with different syntactic bracketing to Ss. The analysis of Experiments 3 and 4 also strongly suggests that lexical material effects do not influence the results, since there were no significant differences between mean reaction times for two groups of Ss, each of which heard different versions of each pair of sentences. Moreover, examination of Tables 3 and 4 shows that probes coming from the final clause were always recognized faster than probes coming from the initial clause in both intramodal and crossmodal experiments in both groups. Thus, Experiments 3 and 4 show that on both intramodal and crossmodal probe tasks, the position of the probed word vis-a-vis a clause boundary in a complex sentence-independent of intonation differences, erial position effects, or lexical material effects-influences reaction times of $S s$. When a probe is within the final clause, recognition latencies are lower than when it is before the final clause. These results reinforce the hypothesis that clause boundaries are primary units in the segmentation of sentences in perception.

\section{REFERENCES}

GARRETT, M. Syntactic structures and judgements of auditory events. Unpublished doctoral dissertation. University of Illinois, 1965.

GARRETT, M. Perceptual complexity and the segmentation of sentences. In $T$. Bever and W. Weschel (Eds.), The structure and psychology of language. Unpublished mimeograph, Massachusetts Institute of Technology, 1966.

WALKER, E. C. T. Grammatical relation and sentence memory. Unpublished doctoral dissertation. University of Indiana, 1969a.

WALKER, E. C. T. Grammatical relations and sentence memory. Paper presented to Linguistic Society of America, $1969 b$.

WALKER, E. C. T. Structure in sentence memory. Quarterly Progress Report No. 96, Research Laboratory of Electronics, M.I.T.. 1970.

WALKER, E. C. T., GOUGH, P. B., \& WALL, R. E. Grammatical relations and the search of sentences in immediate memory. Paper presented to the Midwest Psychological Association, 1968.

(Received for publication A ugust 26, 1971.)

APPENDIX A

INTRAMODAL AND CROSSMODAL TEST FOR CLAUSE BOUNDARY EFFECTS

Major Break 5 Syllables from End: Probe (italicized) BEFORE Last Clause:

1. Every time we visit friends, we bring them liquor.

2. If enough money is raised, we'll stop pollution.
3. If my husband comes in time, we'll buy some new clothes.

4. When you go to France to live, you'll learn to like cheese.

5. Unless you want beans for lunch, don't eat at Eddie's.

6. No matter how hard we push, we'll never move it.

7. If you liked his first novel, you should read this one.

8. Unless a great change occurs, all our stocks will fall.

Major Break 5 Syllables from End; Probe (italicized) WITHIN Last Clause:

1. When interest rates fall on bonds, stocks also go down.

2. If you visit Chicago, see the stock-yard gates.

3. To see the movie actress, men stood on car roofs.

4. Unless the wine is too cold, put it back on ice.

5. Even though the book is old, parts are still modern.

6. If you want to gain more strength, eat proteins daily.

7. Whenever you need a loan, banks are most helpful.

8. Before you sign a new lease, check all the fine print.

Major Break 4 Syllables from End; Probe (italicized) BEFORE Last Clause:

1. Though the forecast calls for more rain, the sun is out.

2. Whenever my wife cleans and cooks, I give her gifts.

3. When a pitcher throws a curve ball, his body turns.

4. No matter what the students say, they will all pass.

5. Although we don't get good results, we keep trying.

6. Every time my friend tried to phone, I wasn't in.

7. Unless this line is drawn in ink, it will soon fade.

8. Even if the soup does improve, you can't eat it.

Major Break 4 Syllables from End; Probe (italicized) WITHIN Last Clause:

1. If Jane plays any Beatles' songs, guests will soon leave.

2. If Sue decides to ask for help, give her this book.

3. If you want to kick a field goal, hold the ball straight.

4. Though no one appeared friendlier, fights were ended.

5. Whenever it rains very hard, trees seem greener.

6. If the wine is exposed to air, drink it at once.

7. No matter what these reports say, planes are quite cheap.

8. If you need some more exercise, run fifty yards.

Major Break 3 Syllables from End; Probe (italicized) BEFORE Last Clause:

1. Even if the rain never does stop, we will leave.

2. Once you learn a new way to lose weight, let Jane know.

3. No matter how carefully you scheme, crime won't pay.
4. Whenever this man wants a new coat, he calls us.

5. No matter how little you do drive, tires wear out.

6. Unless John says he phoned up his girl, don't ask him.

7. If this book says those tacks will hold, buy some now.

8. Although the patient now wants a cure, he must wait.

Major Break 3 Syllables from End. Probe (italicized) WITHIN Last Clause:

1. Whenever this goalie stops the puck, fans go wild.

2. Unless your plan is new and daring. change it now.

3. When management does not raise wages, strikes result.

4. If you want friends to think you are rich, serve good Scotch.

5. No matter how you try to clean it, lint stays on.

6. Even though the question is minor, think it through.

7. Though some disagreements still exist, peace is near.

8. When this batter hits a hard line drive, watch him run.

APPENDIX B

INTRAMODAL AND CROSSMODAL TEST FOR CLAUSE BOUNDARY EFFECTS

(CONTROL FOR LEXICAL MATERIAL AND INTONATION)

1. Now that artists are working in oil, prints are rare.

Now that artists are working fewer hours, oil prints are rare.

2. Although we still have not had any snow, storms are expected.

Because the weather is cold and damp, snow storms are expected.

3. Because cassettes are so popular, tapes are cheap.

Because cassettes are available, popular tapes are cheap.

4. When the granite blocks are very big cranes lift them.

When the granite blocks are raised, big cranes lift them.

5. Even though the TV set is old, parts of it work well.

This TV set was just checked, and old parts of it work well.

6. When the sun warms the earth after the rain, clouds soon disappear.

When a high pressure front approaches. rain clouds soon disappear.

7. Although the total volume of their business is quite small, country stores survive.

Because their clientel is faithful to them small country stores survive.

8. Whenever one telephones at night, rates are lower. 
Make your calls after six, because $n$ ight rates are lower.

9. Unless the temperature drops below freezing, rain will fall.

Unless the storm center moves farther north, freezing rain will fall.

10. If the results of research are successful, businesses start up.

When the government restricts imports, successful businesses start up.

11. Even though their representative is old, voters like him.
Because their representative does them favors, old voters like him.

12. When the school principal decided to become more strict, dress codes were set up.

At the request of several conservative parents, strict dress codes were set up.

13. If you allow them to become wet, shoes will not last.

Even when the workmanship is excellent, wet shoes will not last.

14. If you expose these drapes to the light, colors will fade.

Unless you give them a good second coat, the light colors will fade.

15. If you handle animals in your uork, clothes get dirty.

No matter how much care you take, work clothes get dirty.

16. Because they are extremely slow, busses are safe.

Although riding in them is not very comfortable, slow busses are safe. 